\title{
Estudo da perda da tensao do enxerto de tendão calcâneo bovino
}

Sergio Rocha PIEDADE ${ }^{1}$ Silvestre RODRIGUES ${ }^{2}$

Alessandra Carvalho Tavares

Rocha PIEDADE ${ }^{3}$

Martha Maria MISCHAN ${ }^{4}$

Inácio Maria Dal FABBRO²

\section{Correspondência para:}

Sergio Rocha Piedade, Rua Dr. Carlos Guimarães, 248-apto 114. CEP:13024-200

Campinas-SP piedade@unicamp.br

Recebido para publicação: 06/02/2006 Aprovado para publicação: 13/06/2007

\author{
1 - Faculdade de Ciências Médicas da Universidade de Campinas, Campinas - SP \\ 2 - Faculdade de Engenharia Agrícola da Universidade de Campinas, Campinas - SP \\ 3 - Médica Especialista em Medicina Esportiva \\ 4 - Instituto de Biociências da Universidade Estadual Paulista, Botucatu - SP
}

\section{Resumo}

A lesão do ligamento cruzado anterior do joelho (LCA) é um problema que afeta tanto os animais como os seres humanos, e pode evoluir com instabilidade articular, muitas vezes, sintomática e incapacitante para o paciente. Os enxertos de tendões autólogos são a principal opção como substitutos ligamentares. Durante a reconstrução cirúrgica do LCA, o enxerto é submetido a tensionamento com o objetivo de restabelecer a lassidão normal do joelho LCA-deficiente. Embora o tensionamento do enxerto exerça papel fundamental na evolução clínica pós-operatória, a literatura ainda não estabeleceu os níveis ideais de tensionamento a serem aplicados. Assim, o estiramento ou elongamento do enxerto que pode ocorrer com o passar do tempo permanece como uma das principais causas da falha da reconstrução ligamentar.Neste trabalho, dez tendões de calcâneo bovino foram submetidos a dois ensaios sucessivos de tensionamento fisiológico a deformação relativa máxima de $2.5 \%$ do comprimento inicial do tendão ensaiado, mantida durante $600 \mathrm{~s}$, sendo registrados os valores de força $(\mathrm{N})$ no tempo zero (inicial), 300s e 600s. Ao término do primeiro ensaio, o tendão retornava ao seu comprimento inicial, sendo mantido em repouso durante 300s, seguido de novo ensaio de tensionamento repetindo-se os mesmos procedimentos anteriores. A análise estatística permitiu concluir que o elongamento do tendão é mais pronunciado nos 300s iniciais, refletindo uma queda mais acentuada nos valores da tensão do enxerto. Portanto, 300s após o tensionamento e fixação do enxerto, o cirurgião pode avaliar mais adequadamente se o nível de tensionamento foi suficiente.

\section{Introdução}

A lesão do ligamento cruzado anterior do joelho (LCA) é a principal causa de instabilidade ligamentar desta articulação, sendo um problema que afeta tanto os animais como os seres humanos. ${ }^{1}$ Clinicamente, evolui com um quadro de claudicação, muitas vezes, sintomática e incapacitante para o paciente..$^{2,3,4}$ Neste contexto, a reconstrução cirúrgica do LCA, realizada com enxertos de tendões autólogos ${ }^{5}$, tem como objetivo primário evitar a recorrência da instabilidade sintomática pela restauração da lassidão normal do joelho
Palavras-chave:

Cirurgia veterinária. Tendões.

Enxertos em animais. Ligamento cruzado cranial.

\section{LCA-deficiente ${ }^{6,7,8}$.}

O elongamento excessivo do enxerto, que pode ocorrer com o passar do tempo, constituí-se numa das principais causas de falha da cirurgia de reconstrução ligamentar, sendo a frouxidão ligamentar pós-operatória fator crítico para evolução clínica. ${ }^{910}$

Durante a cirurgia uma das variáveis mecânicas que está sob o controle do cirurgião é a quantidade de tensão aplicada ao enxerto do LCA, no momento da sua fixação. Este tensionamento pode ser realizado de forma cíclica ou estática através de força ou deformação aplicada ao enxerto de tendão. Entretanto, na literatura ainda não 
foi estabelecido o nível ideal de tensionamento a ser aplicado ao enxerto de tendão, permanecendo este assunto um campo aberto a novas pesquisas. Evidências cientificas sugerem que existe um estreito limite para se atingir a tensão inicial ideal do enxerto que permite sua integração e remodelação para um estado estável e maduro. Assim, durante o tensionamento, o limite fisiológico dos tendões deve ser respeitado para que não se produza um sobretensionamento, com conseqüentes efeitos deletérios ao enxerto. De acordo com Abrahams ${ }^{11}$ e Fung ${ }^{12}$, o limite elástico fisiológico de tendões e ligamentos é inferior a $5 \%$ da deformação relativa ao seu comprimento.

Desta forma, o estudo da resposta mecânica apresentada pelos tendões submetidos a tensionamento realizado dentro do limite fisiológico, pode auxiliar na evolução dos procedimentos cirúrgicos e os pacientes, homens e animais com lesão do LCA, se beneficiar desse conhecimento.

Neste trabalho, dez tendões de calcâneo bovino foram submetidos a dois ensaios de tensionamento fisiológico a deformação relativa máxima de $2.5 \%$ do comprimento inicial do tendão ensaiado, mantida durante $600 \mathrm{~s}$, sendo analisado o efeito do elongamento do tendão sobre o tensionamento inicial.

\section{Material e Método}

Foram utilizados dez tendões calcâneo bovino, de macho da raça Nelore, com peso aproximado de $450 \mathrm{kgf}$ e idade média de 3 anos. A necessidade de se manterem as propriedades físicas dos corpos de prova, associada à dificuldade prática de realizar os ensaios no momento da sua obtenção, levaram a estocagem dos tendões à temperatura de $-20^{\circ} \mathrm{C}$.

Para a realização dos ensaios foi feito o descongelamento a temperatura ambiente $\left(27^{\circ} \mathrm{C}\right)$ conforme descrito por diversos autores. ${ }^{13,14,15}$ Os ensaios foram conduzidos numa máquina de ensaios, inteiramente automatizada, modelo TA 500, fabricado pela LLOYD INSTRUMENTS LTD. Este texturômetro, de origem inglesa possui célula de carga de $500 \mathrm{~N}$ e resolução de $0,01 \%$ (Figura 1). O sistema está acoplado a um computador Penthium Pro ${ }^{\circledR}$, com 64 MB de memória RAM. A aquisição automática dos dados foi feita utilizando o "software" Nexygen 3.0.

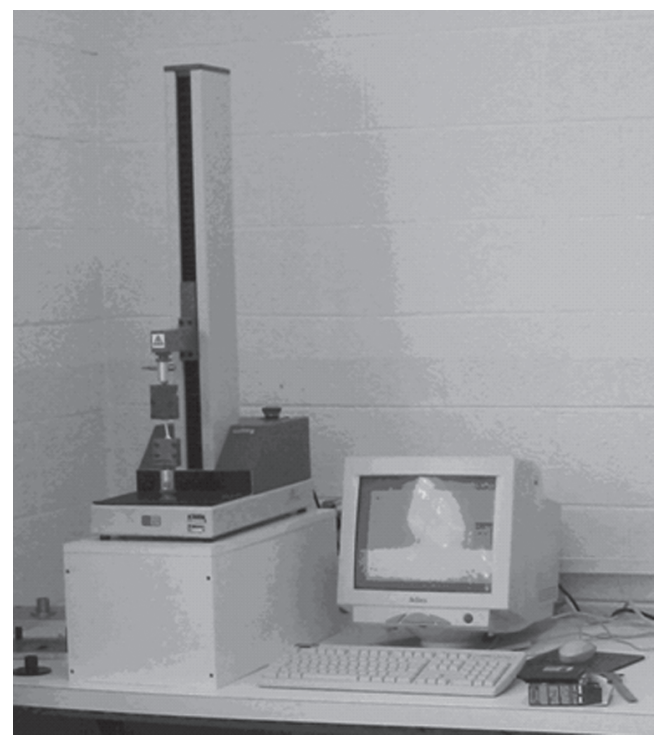

Figura 1 - Texturômetro, modelo TA 500, acoplado a um computador Penthium Pro ${ }^{\circledR}$ e corpo de prova fixado ao sistema de garras

O tendão foi fixado na máquina de ensaios através de um sistema de garras (Figuras 2 -A e 2-B). Este sistema consistiu de duas placas metálicas acopladas uma contra outra e fixas por quatro parafusos que receberam um torque médio de 2,5 N.mm, através de um torquímetro de estalo, modelo AVT 100, marca Bristol, com escala de 2,5 a 11 N.mm. A face interna dessas placas possui ranhuras sinusoidais que conferiu confiabilidade ao sistema de fixação, evitando o escorregamento do tendão durante a realização dos ensaios. A padronização destes procedimentos foi definida após testes preliminares.

Antes de se iniciar os ensaios, foi aplicada uma pré-carga de $2 \mathrm{~N}$ ao tendão para se uniformizar a tensão inicial para todos os tendões estudados. A dificuldade encontrada para se manter um mesmo comprimento inicial (Lo) para todos os 


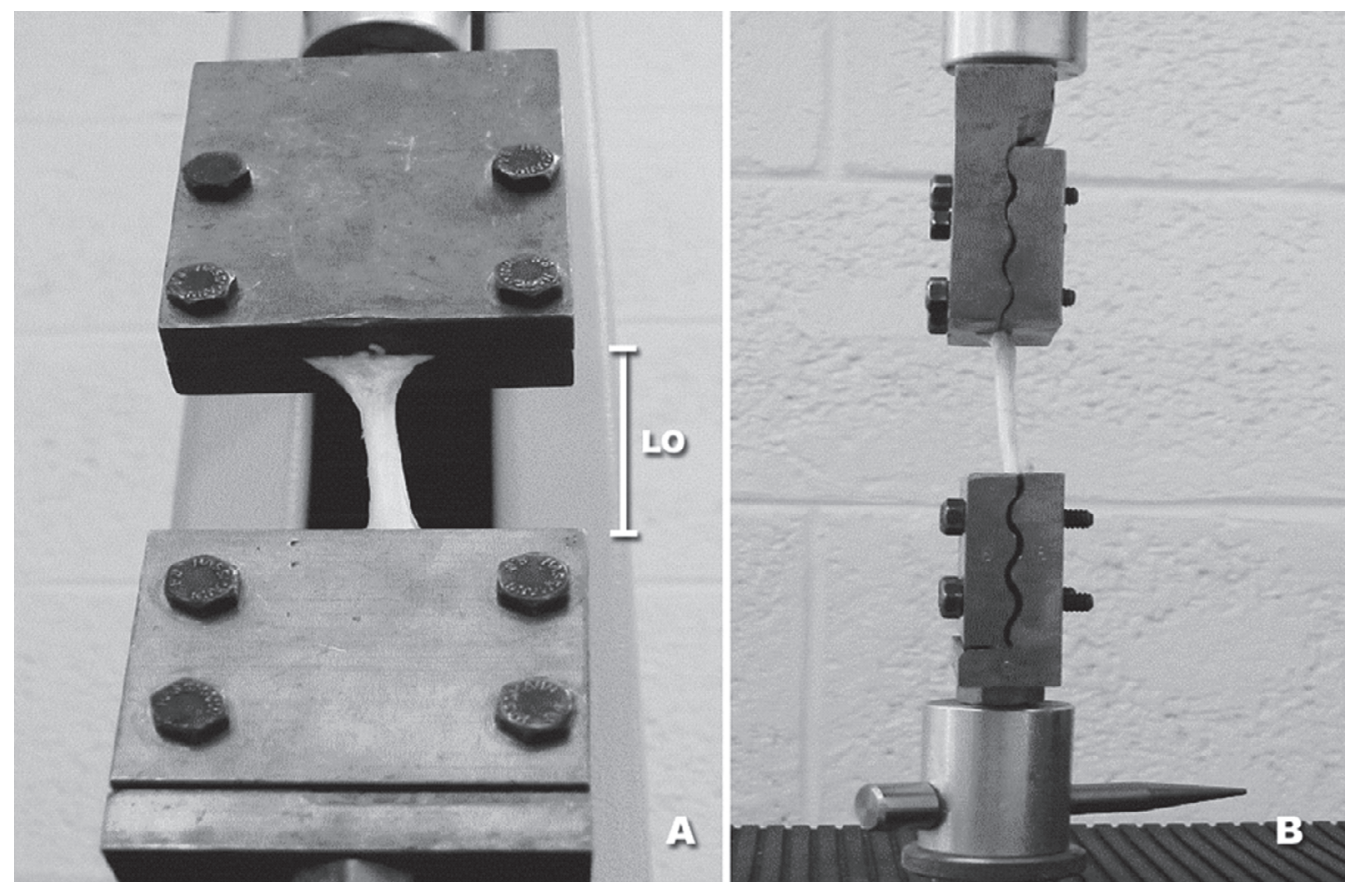

Figura 2 A e B - Detalhe do sistema de garras utilizado nos ensaios: vista de frente (2-A): tendão fixo ao sistema de garras ilustrando a determinaçao do comprimento inicial do corpo de prova (Lo) e vista de perfil (2-B) ilustrando o aspecto sinusoidal das placas metalicas na sua area de contato

tendões durante a sua fixação nos sistema de garras (Figura 2-A) fez com que fosse adotado o conceito de deformação relativa após a medida do comprimento realizada com paquímetro digital, sendo mantido um comprimento médio de 22,15 mm.

Os tendões foram submetidos a dois ensaios sucessivos de tensionamento a uma deformação relativa máxima de $2.5 \%$ do comprimento do tendão (Lo). Este nível de deformação foi adotado por encontra-se dentro do limite fisiológico elástico dos tendões e ligamentos. ${ }^{10,13}$

Durante o ensaio, o tendão foi mantido nesta deformação $(2,5 \%)$ durante 600 s, sendo feito o registro continuo dos valores de força $(\mathrm{N})$ durante este período. Ao término dos $600 \mathrm{~s}$, a deformação era retirada, permitindo ao tendão que retornasse ao seu comprimento inicial (Lo) sendo mantido em repouso de 300s. Após este período, novo ensaio de tensionamento repetindo-se os mesmos procedimentos anteriores (Figura 3).

Vale ressaltar que os ensaios foram conduzidos a uma velocidade de carregamento de $10 \%$ do Lo por segundo.

Durante o $1^{\circ}$ e $2^{\circ}$ ensaios de tensionamento, foram considerados os registros de força tensional gerada por cada tendão no tempo zero (inicial), 300s e 600s do ensaio, durante os 600s de cada ensaio. Os dados obtidos foram submetidos a análise de variância, sendo avaliado o comportamento da queda precoce de tensão do enxerto gerada apos tensionamento fisiológico $(2,5 \%)$.

\section{Resultados}

Os valores de força tensional gerada por cada tendão para se atingir a deformação relativa máxima de 2,5\% do comprimento inicial obtidos no tempo zero, com 300s e 600s de ensaio, durante os dois ensaios sucessivos de tensionamento para os dez tendões de calcâneo bovino estudados, estão apresentados na tabela 1.

$\mathrm{Na}$ tabela 2 são apresentadas as comparações entre médias obtidas através do teste de Tukey para as força no tempo 


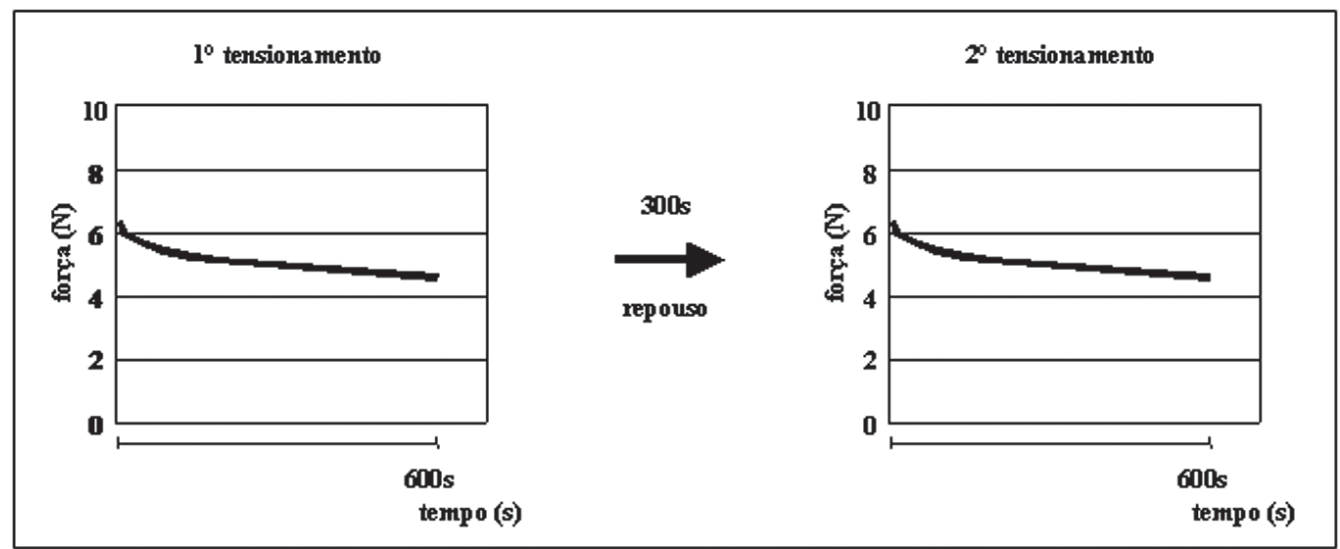

Figura 3 - Esquema ilustrativo dos diagramas gerados durante o $1^{\circ}$ e $2^{\circ}$ ensaio sucessivos de tensionamento, intercalado pelo período de repouso (300s)

Tabela 1 - Valores de força (N) obtidos no tempo zero, 300s e 600s, para os dez tendões de calcâneo bovino submetidos a dois ensaios sucessivos de tensionamento a deformação relativa máxima de $2,5 \%$ do comprimento do tendão ensaiado, com intervalo de repouso de 300 s entre cada ensaio

\begin{tabular}{ccccccc}
\hline & \multicolumn{3}{c}{ tensionamento 1 } & \multicolumn{3}{c}{ tensionamento 2 } \\
\hline $\begin{array}{c}\text { Amostra } \\
\text { (número) }\end{array}$ & tempo zero & $\begin{array}{c}\text { com 300s } \\
\text { de ensaio }\end{array}$ & $\begin{array}{c}\text { com 600s } \\
\text { de ensaio }\end{array}$ & tempo zero & $\begin{array}{c}\text { com 300s } \\
\text { de ensaio }\end{array}$ & $\begin{array}{c}\text { com 600s } \\
\text { de ensaio }\end{array}$ \\
\hline 1 & 5,82 & 2,60 & 2,37 & 6,90 & 4,27 & 3,94 \\
2 & 12,70 & 7,05 & 6,54 & 19,96 & 10,65 & 10,04 \\
3 & 7,91 & 4,13 & 3,84 & 7,10 & 6,38 & 6,10 \\
4 & 10,27 & 4,12 & 3,62 & 10,01 & 5,50 & 4,87 \\
5 & 5,49 & 2,61 & 2,44 & 5,29 & 3,02 & 3,00 \\
6 & 3,19 & 1,44 & 1,25 & 3,32 & 1,82 & 1,70 \\
7 & 9,99 & 6,34 & 6,00 & 11,88 & 8,81 & 8,76 \\
8 & 5,76 & 2,74 & 2,34 & 6,80 & 3,69 & 3,34 \\
9 & 4,48 & 2,38 & 2,12 & 6,14 & 3,55 & 3,32 \\
10 & 5,68 & 2,93 & 2,65 & 6,82 & 4,01 & 3,75 \\
\hline média & $\mathbf{7 , 1 2 9}$ & $\mathbf{3 , 6 3 4}$ & $\mathbf{3 , 3 1 7}$ & $\mathbf{8 , 4 2 2}$ & $\mathbf{5 , 1 7 0}$ & $\mathbf{4 , 8 8 2}$ \\
\hline
\end{tabular}

Tabela 2 - Valores médios de força $(\mathrm{N})$, nos dois ensaios de tensionamento a deformação relativa máxima de 2,5\% do comprimento do tendão ensaiado obtidos para os dez tendões calcâneo bovino estudados, no tempo zero, com 300s e 600s de ensaio. Comparação entre as médias pelo teste de Tukey

\begin{tabular}{lcccc}
\hline Tratamento & zero $\mathbf{s}$ & $\mathbf{3 0 0 s}$ & $\mathbf{6 0 0 s}$ & Médias do ensaio \\
\hline tensionamento 1 & 7,129 & 3,634 & 3,317 & $4,6933(\mathbf{B})$ \\
tensionamento 2 & 8,422 & 5,170 & 4,882 & $6,1580(\mathbf{A})$ \\
Média de tempos & $7,7755(\mathbf{a})$ & $4,4020(\mathbf{b})$ & $4,0995(\mathbf{b})$ &
\end{tabular}

* Médias seguidas de mesma letra não diferem ao nível de $5 \%$ de probabilidade. Letras minúsculas comparam médias na linha e maiúsculas, na coluna

zero, com 300 s e 600 s e os valores dos decréscimos porcentuais de força obtidos até 300s, nos dois ensaios sucessivos de tensionamento estão mostrados na tabela 3.

\section{Discussão}

O joelho de cães e gatos possue estrutura óssea e capsulo-ligamentar semelhante ao joelho do ser humano sendo sítio freqüente de lesão ligamentar, principalmente nos cães e gatos ativos. Com mecanismo de lesão semelhante ao do homem, o LCA é a estrutura mais freqüentemente lesada. ${ }^{1,3} \mathrm{~A}$ instabilidade anterior do joelho determina importante limitação funcional para o paciente, sendo clinicamente identificado pela claudicação e perda de performance do animal. ${ }^{4}$

A reconstrução cirúrgica do LCA com enxerto de tendões autólogos é o procedimento empregado para correção do 
Tabela 3 - Valores porcentuais do decréscimo de força obtidos até 300s, nos dois ensaios sucessivos de tensionamento a deformação relativa máxima de $2,5 \%$, para os 10 tendões de calcâneo bovino estudados

\begin{tabular}{ccc}
\hline & \multicolumn{2}{c}{ \% do decréscimo de força até 300s de ensaio } \\
\hline Amostra (número) & tensionamento 1 & tensionamento 2 \\
\hline 1 & 93,32 & 88,88 \\
3 & 91,68 & 93,90 \\
4 & 92,98 & 72,26 \\
5 & 92,52 & 87,79 \\
6 & 94,52 & 99,16 \\
7 & 90,14 & 92,50 \\
8 & 91,36 & 98,54 \\
9 & 88,25 & 89,78 \\
10 & 88,83 & 91,70 \\
média & 90,89 & 91,44 \\
\hline
\end{tabular}

quadro de instabilidade articular ${ }^{5,9}$. Embora os resultados clínicos pós-operatórios sejam satisfatórios, o elongamento do enxerto e a conseqüente perda da tensão do neoligamento permanecem como uma das causas de falha cirúrgica. Embora a literatura ainda não estabeleça os níveis ideais de tensão a serem aplicados, o tensionamento do enxerto é um procedimento comumente empregado, no intra-operatório, pela grande maioria dos cirurgiões. A tensão ou deformação aplicada ao enxerto, no momento da sua fixação, tem como objetivo conferir ao neo-ligamento a lassidão normal do LCA. Entretanto, vale ressaltar que o limite elástico fisiológico do tendão deve ser respeitado para que não se promova deformações permanentes ao enxerto e sua conseqüente lesão. ${ }^{16}$

A figura 4 ilustra os valores médios de força obtidos no tempo zero (inicial), com 300s e 600s nos dois ensaios consecutivos de tensionamento (Tabela 1). Paralelamente, observa-se com o passar do tempo, ou seja, a partir do tempo zero, decréscimo dos valores de força durante os dois ensaios de tensionamento estudados. Assim, para um mesmo ensaio, o tendão tornou-se mais deformável.

Comparando-se as médias de forças obtidas para o $1^{\circ}$ e $2^{\circ}$ tensionamento observa-se que existe diferença significativa dos valores de força obtidos no tempo zero em relação às demais (300s e 600s). Além disso, a partir de 300 s de ensaio de tensionamento não existe diferença estatística entre os valores de força até o final do ensaio (600s). Esta análise sugere que a perda precoce da tensão do enxerto submetido a tensionamento é mais pronunciada nos primeiros 300s após sua fixação. Passados os 300s iniciais do ensaio ocorre uma tendência de estabilização dos valores de decréscimo de força.

A seguir, foi realizada a análise do valor médio percentual da perda precoce da força até 300s, obtidos nos dois ensaios (Tabela 3). Nesta avaliação não foi constatada diferença significativa entre os dois ensaios. Este resultado pode estar associado ao cálculo da porcentagem se constituir num mecanismo de uniformização dos dados. Desta forma, o comportamento da perda porcentual ate 300 s de ensaio estaria localizado numa distribuição semelhante para os dois grupos ( $1^{\circ}$ e 2 tensionamento).

Portanto, a análise estatística permitiu concluir que o elongamento do enxerto é mais pronunciado nos 300s iniciais do ensaio, resultando queda mais acentuada nos valores da tensão do enxerto. Esta constatação é importante para o cirurgião, pois pode 


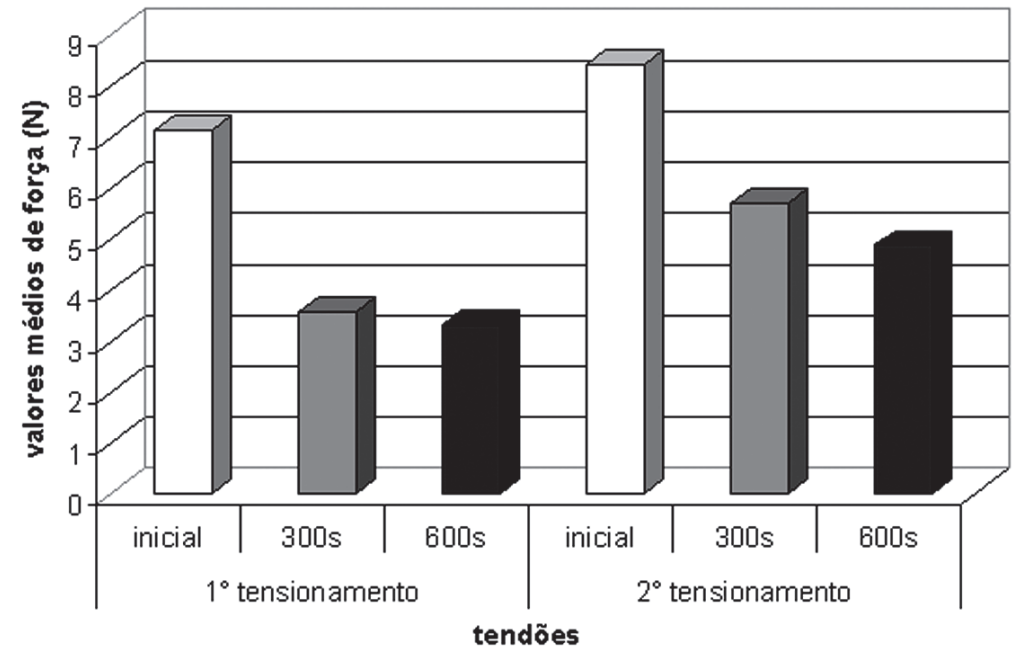

Figura 4 - Valores médios de força inicial, com 300s e 600s, obtidos para o tendão calcâneo bovino, submetidos a dois ensaios sucessivos de relaxamento estático de força, com intervalo de 300s

auxiliar na avaliação do tensionamento instituído ao enxerto, assim como, definir uma estratégia de tensionamento durante o intra-operatório.

\section{Conclusões}

$\mathrm{Na}$ presente pesquisa, com a metodologia empregada, os resultados permitiram concluir que no tensionamento do enxerto de tendão realizado dentro de limites fisiológicos, o elongamento do tendão é mais pronunciado nos 300s iniciais, refletindo queda mais acentuada nos valores da tensão do enxerto. Portanto, transcorrido 300s após o tensionamento e fixação do enxerto o cirurgião pode avaliar mais adequadamente o arco de movimento e estabilidade articular do joelho, assim como, se o nível de tensionamento instituído ao enxerto do tendão foi suficiente para se restabelecer a lassidão normal do LCA do joelho.

\section{Tension loss of a bovine calcaneus tendons}

\section{Abstract}

Lesion of the anterior cruciate ligament (ACL) in the knee is a problem that affects animals as well as humans and may evolve with joint instability that is often symptomatic and incapacitating. The main option for ligament substitution is the autologous tendon graft. The graft undergoes tensioning during ACL reconstructive surgery to reestablish the normal laxity of the ACL- deficient knee. Although graft tensioning plays a fundamental role in postoperative clinical evolution, ideal tensioning levels have not been established in the literature. Therefore, graft elongation that may occur over time is still one of the main reasons for ligament reconstruction failure. In this study, ten bovine calcaneus tendons underwent two successive assays of physiological tensioning for a maximum deformation of $2.5 \%$ of the initial tendon length, maintained for 600 s with force $(\mathrm{N})$ values recorded at zero time (initial), 300s and 600s. At the end of the first assay, the tendon returned to its initial length and was maintained at rest for 300 s and then the next tensioning assay was initiated, repeating
Key words:

Surgery veterinary.

Tendons.

Graft.

Anterior cruciate ligament. 
the previous procedure. Statistical analysis revealed that tendon elongation is more pronounced during the initial 300s, reflecting a more accentuated decline in the tension values of the graft. Therefore, 300s after tensioning and fixing the graft, the surgeon can assess with more precision if the tensioning level was adequate.

\section{Referências}

1 WHITEHAIR, J. G.; VASSEUR, P. B. ; WILLITS, N. $\mathrm{H}$. Epidemiology of cranial cruciate ligament rupture in dogs. J Am Vet Med Assoc, v. 203, n. 7, p. 10161019, 1993.

2 BRANDT, K. D. et al. Anterior (cranial) cruciate ligament transection in the dog: a bona fide model of osteoarthritis, not merely of cartilage injury and repair. J Rheumatol, v. 18, n. 3, p. 436-446, 1991.

3 LOPEZ, M. J. et al. A comparison of joint stability between anterior cruciate intact and deficient knees: a new canine model of anterior cruciate ligament disruption. J Orthop Res, v. 21, n. 2, p. 224-230, 2003.

4 TASHMAN, S. et al. Kinematics of the ACL-deficient canine knee during gait: serial changes over two years. J Orthop Res, v. 22, n. 5, p. 931-941, 2004.

5 LOPEZ, M. J. et al. Hamstring graft technique for stabilization of canine cranial cruciate ligament deficient stifles. Vet Surg, v. 32, n. 4, p. 390-401, 2003.

6 INNES, J. F. Long-term outcome of surgery for dogs with cranial cruciate ligament deficiency. Vet Rec, v. 147 , n. 12, p. 325-328, 2000.

7 HOELZLER, M. G. et al. Results of arthroscopic versus open arthrotomy for surgical management of cranial cruciate ligament deficiency in dogs. Vet Surg, v. 33, n. 2, p. 146-153, 2004.

8 CONZEMIUS, M. G. et al. Effect of surgical technique on limb function after surgery for rupture of the cranial cruciate ligament in dogs. J Am Vet Med Assoc, v. 226, n. 2, p. 232-236, 2005.

9 TOHYAMA, $\mathrm{H}$. et al. The effect of anterior cruciate ligament graft elongation at the time of implantation on the biomechanical behavior of the graft and knee. Am J Sports Med, v. 24, n. 5, p. 608-614, 1996.

10 MIKAMI, S. et al. Reduction of initial tension in the in situ frozen anterior cruciate ligament. Clin Orthop Relat Res, v. 419, p. 207-213, 2004.

11 ABRAHAMS, M. Mechanical behavior of tendon in vivo. Medical and Biological Engineering, v.5,n.5 p. 433-443, 1967.

12 FUNG, $\mathrm{C}$. The meaning of the constitutive equation In: FUNG, Y. C. Biomechanics - mechanical properties of living tissues. New York: Springer, 1990. p. 23-65.

13 MATTHEWS, L. S.; ELLIS, D. Viscoelastic properties of cat tendon: effects of time after death and preservation by freezing. Journal of Biomechanics, v. 1, n. 2, p. 6571, 1968.

14 WOO, S. L. Y. et al. Effects of postmortem storage by freezing on ligament tensile behaviour. Journal of Biomechanics, v. 19, n. 5, p. 399-404, 1986.

15 PFAFFLE, H. J. et al. Short communication tensile properties of the interosseus membrane of the human forearm. Journal of Orthopaedic Research, v. 14, n. 5, p. 842-845, 1996.

16 KATSURAGI, $R$. et al. The effect of nonphysiologically high initial tension on the mechanical properties of in situ frozen anterior cruciate ligament in a canine model. Am J Sports Med, v. 28, n. 1, p. 47-56, 2000. 